\title{
Body Image Dissatisfaction in The Youth of India: And the Effects on Self-Esteem
}

\author{
Bhawini Vasudeva ${ }^{1 *}$
}

\section{ABSTRACT}

The aim to conduct this research is to enlighten the impact of body image dissatisfaction on an individual's self-esteem and to examine whether there is a gender difference in this case or not. There are a total of 220 numbers of participants, with equal number of males and females in the sample set. The tool that'd be using here is a modified short version of the Body Shape Questionnaire (BSQ) by Cooper et. Al. in the year in 1987 and The Rosenberg self-esteem scale by Morris Rosenberg (RSES) in the year 1965. The current research proved that whenever there'll be higher body image dissatisfaction, it'll result in less self-esteem. Other than that, it stated that females $(\mathrm{M}=22.69$ and $\mathrm{SD}=3.64)$ have a higher mean score in body image dissatisfaction than and males $(\mathrm{M}=23.28$ and $\mathrm{SD}=3.6)$, therefore, the men have a higher mean score of self-esteem than females.

\section{Keywords: Body Image, Self-Esteem, Ideal Self, Self Efficacy}

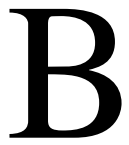
ody image dissatisfaction (BID) is how and in what manner a person sees themselves' and what are the thoughts that come into their head after seeing their physical appearance. Body image is defined as a negative emotional assessment of the weight and state of own body (Ricciardelli et. Al.; 2010). It's stated that body image and mental well-being are highly interrelated even though being two completely different entities of our life (Kostanski and Gullone;1998). Basically, there are numerous factors that play a major role in influencing our body image dissatisfaction or satisfaction, including, genetics, social, cultural, or media exposure (Ferrari, Petroski, Silva; 2013). A person's impression of self-perception impacts his mental working and prosperity. It's a multidimensional psychological, emotional, and conduct reaction to their own physical appearance (Muth and Cash; 1997). In one of the studies, it was stated that not only in females, but there has been the detection of BID and related conduct issues in males in a large number (McCabe and Ricciardelli; 2001), and in the other, it was examined that girls are mostly linked to the correlation of body image dissatisfaction and self-esteem whereas boys aren't affected by body image dissatisfaction (Furnham, Badmin \& Sneade; 2010).

It was also stated that perceived body image dissatisfaction is a repercussion of anxiety, selfesteem, and depression (Kostanski and Gullone; 1998). There are mammoth amount of

\footnotetext{
${ }^{1}$ Student of Amity Institute of Psychology and Allied Sciences, Amity University, Noida, UP, India *Corresponding Author

Received: June 16, 2021; Revision Received: July 24, 2021; Accepted: August 14, 2021
}

(C) 2021, Vasudeva B.; licensee IJIP. This is an Open Access Research distributed under the terms of the Creative Commons Attribution License (www.creativecommons.org/licenses/by/2.0), which permits unrestricted use, distribution, and reproduction in any Medium, provided the original work is properly cited. 
causes behind BID, some of them are the sense of muscularity, self-confidence and mental health (Furnham \& Calnan; 1998), eating behavior and addiction (Drewnowski \& Yee 1987), achievement in life (McCabe, Ricciardelli \& Finemore; 2002) school absenteeism (Yanovar \& Thompson; 1998). There are multiple studies in which it was stated that Body Image Dissatisfaction can be a cause for mental, physical, and social issues like social anxiety (Archibald;2010), depression (Shephard;1998), and suicidal ideation (Brausch;2007).

Self-esteem refers to how and what a person perceives about his/her own worth, this could be a positive or a negative attitude towards the same (Rosenberg;1965). Self-esteem has been conceptualized as a result, intention, and cradle, however, there is no general hypothesis of it (Cast and Burke;2002). Physical appearance serves changed capacities in males and females with similar importance for both self-confidence and self-assurance (Coyl; 2009). Individuals who had higher body image concerns were reported to have relatively less self-esteem (Tiggemann; 2005). Self-esteem is composed of two dimensions: Competence and Worth, the competence measurement or self-efficacy alludes to how much individuals consider themselves to be competent and effective and the worth measurement or the self-value alludes to how much people feel they are people of significant worth (Gecas;1982 and Rosenberg;1995)

As the third force in brain science or psychology, humanism is promoted as a response both to the cynical determinism of analysis, with its accentuation on mental unsettling influence, and to the behaviorists' perspective on people latently responding to the climate, which has been scrutinized as portraying individuals as character less-robots. Carl Rogers; in 1995; proposed the relationship and correlation between the Ideal Self and the Real Self, and as the conclusion, he stated that the more discrepancy between the ideal-real self of an individual with result in more negative attributes. All the more explicitly, convictions about real selfperception are portrayed by an illustrative connection. Conversely, convictions about ideal self-perception relate oneself to body size as far as an attractive quality. Body Image dissatisfaction, nonetheless, by definition contains in excess of a basic relationship between oneself and body size since it is driven by the (apparent) disparity between one's ideal and real self-perception There are many kinds of research on this correlation, one of the articles examined self-esteem as the major risk and preventive factor of body image dissatisfaction $\left(O^{\prime} D e a ; 2010\right)$. It was predicted that girls want to be lighter and boys want to be muscular and heavier (Furnham, Badmin \& Sneade; 2010). Likewise, young ladies who were profoundly overweight revealed lower actual confidence than young ladies who were respectably overweight. Notwithstanding, for young men, the contrary example arose. For the two young men and young ladies, psychological and social confidence anticipated general confidence and actual confidence didn't (Israel \& Ivanova; 2002). It was studied that in western cultures, girls in the adolescent age are more likely to have a major drop in their self-esteem, and growing body image concern could be a more specific explanation for this issue (Clay, Vignose, and Dittmar; 2005). Taking the studies and perspectives into consideration, the current study has been designed to assess the effects and importance of body image dissatisfaction and self-esteem in one's life.

\section{Hypothesis:}

- Hypothesis 1: If an individual's body image dissatisfaction is increased, their selfesteem will be decreased.

- Hypothesis 2: Females have relatively higher body image dissatisfaction than Males. 


\section{METHOD}

\section{Participants}

There were in total 220 number of participants with 110 males $(M=23.28, S D=3.6)$ and 110 females $(M=22.69, S D=3.64)$ in the age group of 20 to 35 from different regions of India.

Table no. 1; gender of participants

\begin{tabular}{llllll} 
& & Frequency & Percent & Valid Percent & Cumulative Percent \\
\hline \multirow{2}{*}{ Valid } & female & 110 & 50.0 & 50.0 & 50.0 \\
\cline { 2 - 6 } & male & 110 & 50.0 & 50.0 & 100.0 \\
\cline { 2 - 5 } & Total & 220 & 100.0 & 100.0 & \\
\hline
\end{tabular}

Table no. 2; Geographical region of participants

\begin{tabular}{ll|r|r|r|r} 
& Frequency & Percent & Valid Percent & $\begin{array}{c}\text { Cumulative } \\
\text { Percent }\end{array}$ \\
\hline \multirow{2}{*}{ Valid } & 129 & 58.6 & 58.6 & 58.6 \\
\cline { 2 - 6 } & Delhi & 47 & 21.4 & 21.4 & 80.0 \\
\cline { 2 - 6 } & DelhiNCR & 20 & 9.1 & 9.1 & 89.1 \\
\cline { 2 - 6 } & Maharashtra & 10.9 & 10.9 & 100.0 \\
\cline { 2 - 6 } & Uttar Pradesh & 24 & 100.0 & 100.0 & \\
\cline { 2 - 6 } & Total & 220 & &
\end{tabular}

Table no.3; Age brackets of participants

\begin{tabular}{llllll} 
& & Frequency & Percent & Valid Percent & Cumulative Percent \\
\hline Valid & $20-27$ & 148 & 67.3 & 67.3 & 67.3 \\
\cline { 2 - 6 } & $28-35$ & 72 & 32.7 & 32.7 & 100.0 \\
\cline { 2 - 4 } & Total & 220 & 100.0 & 100.0 & \\
\hline
\end{tabular}

\section{Tools}

- Body Shape Questionnaire (BSQ- 16a): It was first given by Cooper, P.J., M.J. Taylor, Z. Cooper and C.G. Fairburn in the year 1986. Later its modified short versions came into the play and it comprises of 16 questions 6-Likert scale answers (never, rarely, sometime, often, very often, and always) by Evans and Dolan (1993) analyzing the score of how much an individual is concerned or dissatisfied with its own body shape. The internal reliability of English modified BSQ-16a is ranged from .92 to .96 .

- Self-esteem measure by Rosenberg: It was proposed by Morris Rosenberg in the year 1965, it comprises of 10 questions and 4-Likert Scale answers ranging from (1) strongly agree to (4) strongly disagree. Its internal test-retest reliability ranges from .85 to .88 .

\section{Procedure}

The first step was to arranging and deciding the sample. After doing so, questionnaires were spread to the targeted audience and they were given clear instructions about aim of the study and as well as how are they supposed to answer to all the questions. Sample was also ensured about the confidentiality and no judgments as some of them were feeling shy before filling the form. After collecting the data, the forms were divided into 10 groups of 22 forms each to make it easier for the researcher to go through the answer thoroughly as it lead to complete the scoring and doing the analysis. 


\section{RESULTS}

To test the first hypothesis, the mean score of body image dissatisfaction $(\mathrm{M}=40.81$, $\mathrm{SD}=16.024)$ and mean score of self-esteem $(\mathrm{M}=19.66, \mathrm{SD}=7.291)$ of all the participants were compared and analyzed, it was stated that increasing of body image dissatisfaction leads to decreasing of self-esteem and it was approved by the statistically significant value of $\mathrm{t}(\mathrm{t}=20.192, \mathrm{p}=.001)$. After putting the data under Pearson's correlation we got the results where $\mathrm{r}=0.342 \& \mathrm{p}=<0.01$. It shows that there is a significantly negative relationship between body image dissatisfaction and self-esteem with the $11 \%$ variance and the correlation being significant at 0.01 level(2-tailed).

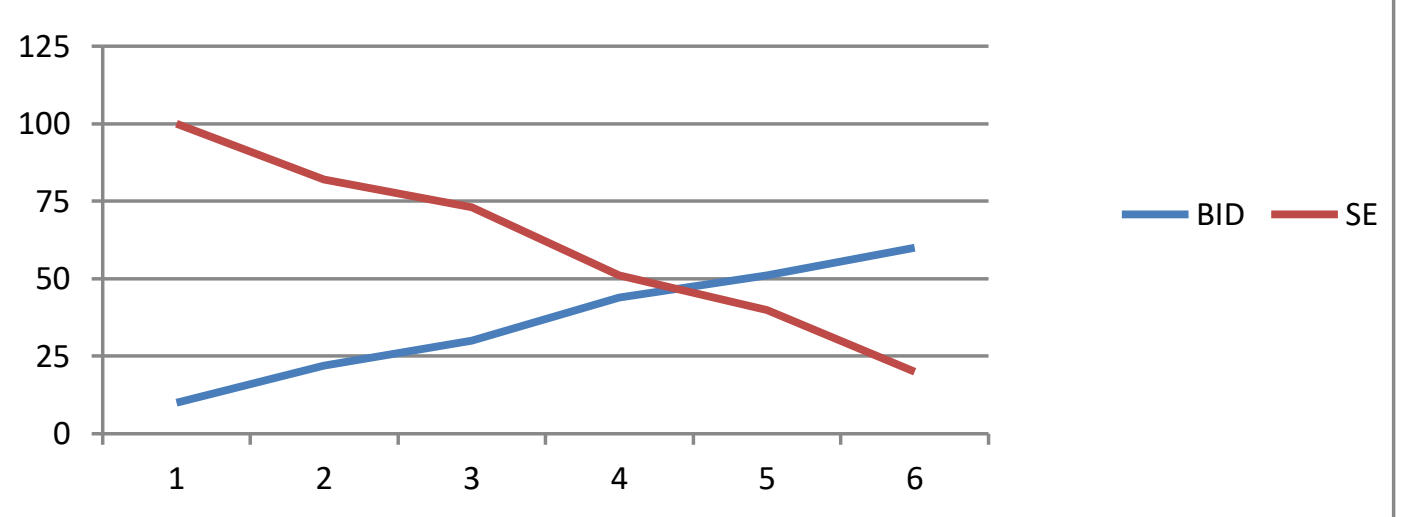

Graph1; increasing of Body Image Dissatisfaction leads to decreasing of Self-esteem

To test the second hypothesis, the mean score of body image dissatisfaction of males and females were compared and analyzed through one-way ANOVA. As the result was calculated, it came across that females $(M=46.52, \mathrm{SD}=17.687)$ tend to have higher body image dissatisfaction than males $(\mathrm{M}=35.11, \mathrm{SD}=11.721)$. The body image dissatisfaction score differs significantly somewhere between the groups and the gender among the participants had a significant impact on body image dissatisfaction scores; $f(1,218)=31.804$ and $\mathrm{p}=<.001$.

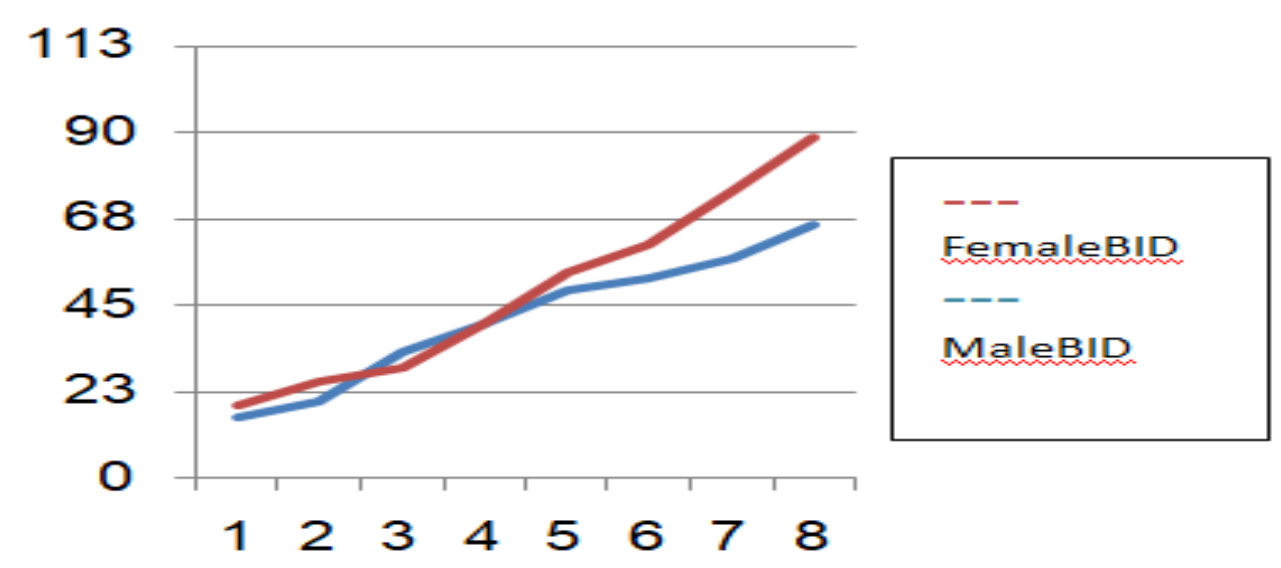

Graph2; it indicated the higher body image dissatisfaction in females than in males

\section{DISCUSSION}

The conclusion of the present study stated that there is an apparent relationship between body image dissatisfaction and self-esteem of an individual. Results of the data analysis indicated that body image dissatisfaction and self-esteem are significantly associated $(\mathrm{p}<0.01)$, which supported the first hypothesis. This shows that increasing body image

(c) The International Journal of Indian Psychology, ISSN 2348-5396 (e)| ISSN: 2349-3429 (p) | 611 
concerns will lead to decreasing of self-esteem, body image dissatisfaction was a significant predictor of the self-esteem (criterion) as $\mathrm{f}(218)=28.83, \mathrm{p}=0.05$ and $r^{2}=0.11$. This study was parallel to studies where discoveries showed a positive correlation between the degree of confidence linked to the body image and self-esteem in the adolescents (Qurat-Ul-Ain and Ajmal; 2019), and individuals with lower lesser self-esteem are progressively liable to report dissatisfaction with their body size or shape, regardless to their age or sex. Since selfconcept addresses an enormous piece of an individual's self-esteem, it is obvious that esteem and body disappointment/dissatisfaction are connected (O'Dea; 2012). Findings support proposals that perceived body image dissatisfaction arises from a complex interplay of factors, including gender, self-esteem, and actual body mass. (Kostanski and Gullone; 1998). Understanding developmental trends and gender differences in self-esteem can enhance our ability to assist youth who are overweight in maintaining favorable selfevaluations (Ivanova and Israel; 2002).

Other than that, this study proposed that there is a significant difference among the scores of body image dissatisfaction of males and females, where in females have relatively higher score on body image dissatisfaction and lesser self-esteem because of the same. Results of the current study are somewhat parallel to the study done on the students of the University of Sharjah, it concluded that female participants were more keen to lose weight where as male participants were more into gaining weight and exercising $(\mathrm{p}<0.001)$, here, Body Mass Index showed a huge strong correlation with the BID $(r=0.57, p<0.001)$. The results featured the need to increase awareness of the importance of smart eating behaviors and regular physical exercises to improve body size, shape perception, and fulfillment among school guys and females (Radwan et. Al; 2019).

While doing the research work, I note that in Psychology, Body image dissatisfaction is something proposed in girls, by external forces (American psychological association; task force on sexualization of girls; 2007), for example, young ladies might be conditioned by the media to be disappointed with their bodies on the off chance that they don't adjust to the slight ideal. Females do appear to have competition issues with evaluating their own body image. However the presence of body image dissatisfaction is high in females as well as in males to some extent and the main cause behind this whole idea of ideal body could be the environment and the external forces which push an individual to the verge of hampering their physical and mental health. The present study suggest future researchers to evaluate the different external factors or powers which follow up on the people to decide the nature and degree of body image and self concept one should try and have in their lives in significance of building oneself.

\section{REFERENCES}

Satghare, P., Mahesh, M., Abin, E., Chong, S.A. and Subramaniam, M. (2019). The relative Association of body image dissatisfaction among psychiatric out patients in Singapore. International Journal of environmental research and Public health, 16(24), DOI: $10.3390 /$ ijerph16245162

Radwan, H., et. Al. (2019). Body mass index perception, body image dissatisfaction and the relation with weight related behaviour among University students. International Journal of environmental research and Public health, 16, 1541, DOI:10.3390/ijerph16091541

Quittkat, H. L., Hartman, A.S., Dusing, R., Buhlmann, U., Vocks, S (2019). Body dissatisfaction, importance of appearance and body appreciation in men and women over the lifespan. Frontiers in psychiatry, 10, DOI: 10.3389/fpsyt.2019.00864 
Ajmal, A. And Qurat-Ul-Ain, (2019). The impact of body image on self-esteem in Adolescents. Clinical and counselling psychology review, 1, DOI: 10.32350/ccpr.11.04

Moffitt, R.L., Neumann, D.L., and Williamson, S.P. (2018). Comparing the efficacy of a brief self-esteem and self-compassion intervention for state body dissatisfaction and self-improvement. $\quad$ Elsevier, $27, \quad 67-76, \quad$ DOI: https://doi.org/10.1016/j.bodyim.2018.08.008

Heider, N., Spruyt, A., and Houwer, J. D. (2018). Body dissatisfaction revisited: on the importance of implicit beliefs about the actual and ideal body image. Belgian Association of psychological science, 57(4), 158-73, DOI: http://doi.org/10.5334/pb.362

Heider, N., Spruyt, A., and Houwer, J. D. (2015). Implicit beliefs about the ideal body image predict body image dissatisfaction. Frontiers in psychology, 6, DOI: 10.3389/fpsyg.2015.01402

Cohen, R., and Blaszczynski, A. (2015). Competitive effects of Facebook and conventional media on body image dissatisfaction. Journal of eating disorder, 3(1), 23. DOI: $10.1186 / \mathrm{s} 40337-015-0061-3$

Tiwari, G. K. (2015). Body image satisfaction enhance self-esteem. Vaichariki, 4(4), DOI: https://www.researchgate.net/publication/271708907

Bazarganipour, F., Ziaei, S., Montazeri, A., Foroozanfard, F., Kazemnejard, A., Faghihzadeh,S. (2013). Body image satisfaction and self-esteem status among the patients with polycystic ovary syndrome. Journal of reproductive medicine, 11(10), 829-36

Ferrari, E. P., Petroski, E. L., Silva, D.A., (2013). Prevalence of body image dissatisfaction and associated factors among physical education students. Trends psychiatry Psychother, 35(2),119-27, DOI: 10.1590/s2237-6089201300020005

Krishen, A. and Dominique, W. (2011). Body image dissatisfaction and self-esteem: a consumer centric exploration. Journal of consumer satisfaction, dissatisfaction and complaining behaviour, 24, 90-106

Ricciardelli, L., et. Al. (2010). Body image and self-esteem across age and gender: a shortterm longitudinal Study. Sex roles, 63, 672-681, DOI: 10.1007/s11199-010-9813-3

Van Den Berg, P. A., Mond, J., Eisenberg, M., Ackard,D., Sztainer, D. A. (2010). The link between body dissatisfaction and self-esteem in adolescents: similarities across gender, age, weight, status, race/ethnicity and socioeconomic status. Journal of adolescent health, 47(3), DOI: 10.1016/j.jadohealth.2010.02.2004

Koyuncu, M., Tok, S., Canpolat, A., Catikkas, F. (2010). Body image satisfaction and dissatisfaction, social physique anxiety, self-esteem and body fat ratio in female exercises and non-exercise. Social behaviour and personality: an international Journal, 38, 561-570, DOI: 10.2224/sbp.2010.38.4.561

Xu, X., Mellor, D., Kiehne, M., Ricciardelli, L. A., McCabe, M.P., Xu, Y. (2009). Body dissatisfaction, engagement and body change behaviours and sociocultural influence on body image among Chinese adolescents. Body image, 7(2), 156-64, DOI: 10.1016/j.bodyim.2009.11.003

Peplau, L.A., et. Al. (2009). Body image satisfaction in heterosexual, gay and lesbian adults. Arch sex behaviour, 38, 713-25, DOI: https://doi.org/10.1007/s10508-008-9378-1

Pook, M., Tuschen-Caffier, B., Bräed, E. (2008). Evaluation and comparison of different version of body shape questionnaire. Psychiatry research, 158(1), 67-73. DOI: 10.1016/j.psychres.2006.08.002 
Croghan, I. T., et. Al. (2006). Is smoking related to body image satisfaction, stress, and selfesteem in young adults. Journal of health behaviour, 30(3), 332-333, DOI: 10.5555/ajhb.2006.30.3.322

Dohnt, H., Tiggemann, M. (2006). The contribution of peer and media influences to the development of body satisfaction and self-esteem in young girls: a prospective study. Developmental psychology, 42(5), 929-36, DOI: 10.1037/0012-1649.42.5.929

Rumsey, N., Harcourt, D. (2004). Body image and disfigurement: issues and intervention. Body image, 1(1), 83-97, DOI: 10.1016/S1740-1445(03)00005-6

\section{Acknowledgement}

The researcher acknowledges the supervisor's guidance and participant's honesty and support towards this research.

\section{Conflict of Interest}

The author(s) declared no conflict of interest.

How to cite this article: Vasudeva B. (2021). Body Image Dissatisfaction in The Youth of India: And the Effects on Self-Esteem. International Journal of Indian Psychology, 9(3), 608-614. DIP:18.01.058.20210903, DOI:10.25215/0903.058 